\title{
Hipospadias ve erkek cinsel sağlığı
}

\section{Hypospadias and male sexual health}

\author{
Fikret Erdemir'1 Ufuk Șenel ${ }^{2}$
}

\section{öz}

Hipospadias erkek canlı doğumlarının 300'de birinde görülen nispeten yaygın konjenital uretral anomalidir. $\mathrm{Bu}$ anomali uretranın penisin ventral yüzündeki anormal lokalizasyonu ile karakterizedir. Uretra glans penisten perineye kadar olan penisin ventral yüzündeki herhangi bir alan boyunca olabilir. Uretral açılımların çoğu glans penis üzerinde ya da yakınlarında iken \%10 olguda meatus perine ve proksimal kısım arasındadır. $\mathrm{Bu}$ anaomalide geleneksel tedavi yaklaşımı cerrahi tamiri içermektedir. 1890 'lı yıllardan günümüze kadar hipospadias cerrahisinde yüzlerce cerrahi yaklaşım tanımlanmıştır. Cerrahi tedavinin amacı fonksiyonel yeni üretra oluşturmak, penil eğriliği düzeltmek ve kozmetik olarak normal görünümlü penis oluşturmaktır. Hipospadias cerrahisindeki sonuçlar üzerine yapılan araştırmalarda çoğunlukla primer olarak cerrahi teknikler ve fonksiyonel sonuçlar üzerine odaklanılmıştır. Ancak, hastaların kozmetik penil görünümleri ile ilgili algıları ve cinsel işlevler cerrahi tedavi sonrası uzun dönem takiplerde oldukça önemli parametrelerdir. Türkçe literatürde hipospadias ve cinsel işlevlerle ilgili çok az bilgi bulunmaktadır. Bu derlemede, hipospadias ve cinsel işlevler arasındaki ilişki incelemiştir.

Anahtar Kelimeler: Hipospadias, uretral anomali, tedavi, cinsel işlevler

${ }^{1}$ Gaziosmanpaşa Üniversitesi Tıp Fakültesi, Tokat, Türkiye

${ }^{2}$ Özel Marmara Hastanesi, Çocuk Cerrahisi, Kocaeli

Yazışma Adresi / Correspondence:

Prof. Dr. Fikret Erdemir

Bahçelievler Mah. Ülkü Cad. 4. Sok. No: 16, Genç İnşaat. C Blok. D: 2

Merkez 60100 Tokat, Türkiye

Tel. $\quad+903562129500 / 1161$

E-mail: fikreterdemir2003@yahoo.com

Geliş / Received: $\quad$ 17.04.2017

Kabul / Accepted: 06.06.2017

\section{ABSTRACT}

Hypospadias is a relatively common congenital male genital anomaly affecting 1:300 live male births worldwide. This anomaly is characterized by an abnormal localization of the urethra on the ventral surface of the penis. The urethral opening is sited anywhere along the underside of the penis from the glans to the perineum. Most have a distal urethral opening on or near the glans, whereas in $10 \%$ the meatus is located between the proximal shaft and the perineum. In this anomaly, the traditional teatment approach is consist of surgical repair. From 1890s until now, hundreds of surgical procedures have been described for the repair of hypospadias. The aim of surgical repair is to create a functional neourethra, correct penile curvature, and produce a cosmetically normal penile appearance. Most research on the outcomes of hypospadias surgery has focused primarily on surgical techniques and functional outcomes. However patient's perceptions of cosmetic penile appearance and sexual functions are very important parameters after surgical repair in long term follow up period. In Turkish literature very little information is available about hypospadias and sexual functions. In this review the relationship between hypospadias and sexual function was evaluated.

Key Words: Hypospadias, urethral anomaly, treatment, sexual functions.

ler, subkoronal), orta (distal penil, midshaft, proksimal penil) ve posterior (penoskrotal, skrotal, perineal) olarak sınıflandırılan hipospadiasta en sık anterior tip (\%50) görülmektedir (Şekil 1). Bu tipler içerisinde posterior hipospadias proksimal hipospadias olarak da bilinmektedir. Hipospadias cerrahisinde temel amaç fonksiyonel yeni uretra oluşturmak, penil eğriliği düzeltmek, normal cinsel ilişki kurulabilmesi için gerekli fonksiyonel ve estetik görünümlü penis oluşturmaktır. Hipospadias cerrahisinin mümkün olduğunca erken çocukluk döneminde tamamlanması istenmektedir. Böylece çocuğun gelecek dönemlerde yaşayabileceği ruhsal travma ve özgüven yitiminin önlenebileceği düşünülmektedir. Şiddetli hipospadias olarak bilinen ve daha çok mid-penil ya da proksimal lokalizasyonlarda olan ya da ciddi penil eğriliğin eşlik ettiği olgularda, penisin normal şeklinin oluşturulmasına ilave olarak sağlıklı bir cinsel ilişkinin sağlanması da öne çıkmaktadır. Hipospadias cerrahisinde 200'ün üzerin- 


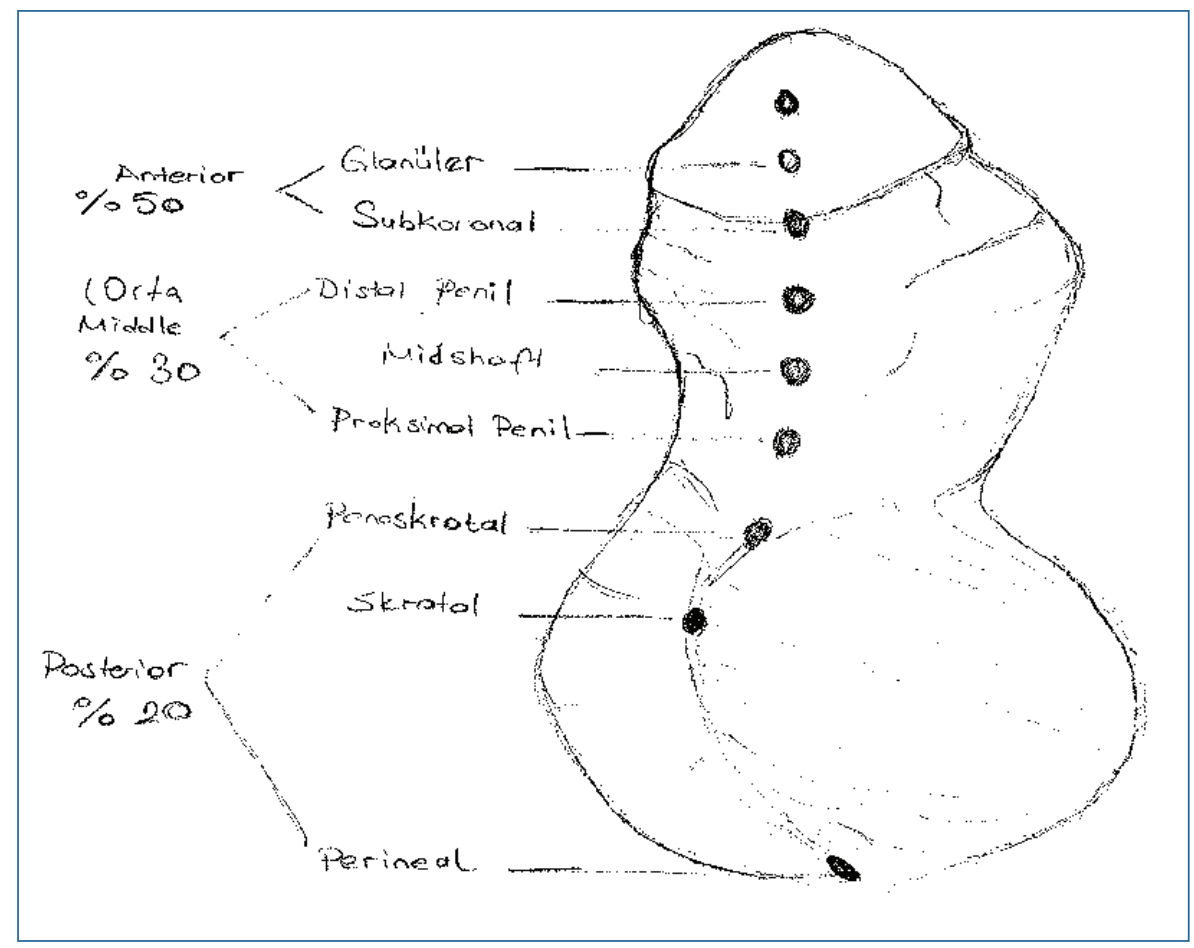

Şekil 1. Hipospadias tipleri ve görülme oranları.

de cerrahi tekniğin olduğu ve yenilerin buna eklendiği anlaşılmaktadır. Yeni tekniklerle elde edilen cerrahi başarıların öncekilere göre daha iyi olduğu görülmektedir. Tüm cerrahilerde olduğu gibi hipospadias cerrahileri sonrasında da erken ya da geç dönemlerde fistül, kanama, enfeksiyon, darlık, persistan hipospadias, üretral kalkül, divertikül, üreral kordi ve üretral kıllanma gibi komplikasyonlar görülebilmektedir.

Günümüzde genç erkeklerin cinsellikten beklentilerinin geçmiş dönemdeki yaşıtlarına göre daha yüksek olduğu düşünülmektedir. Hipospadiaslı olgularda gerek hastalar gerekse de ebeveynler için cerrahi öncesi ve sonrası genital görünüm oldukça önem arz etmektedir. Bracka’nın çalışmasında olguların \%72'si, normal cinsel ve üriner fonksiyonlar kadar normal penis görünümlerinin de kendileri için çok önemli olduğunu bildirmişlerdir. ${ }^{[6]}$ Yukarıdaki çalışmaya benzer şekilde çok sayıda çalışmada penis görünümünün cerrahi tedavi sonrası olgular üzerindeki etkisi araştırılmıştır. ${ }^{[2-4,7-13]}$ İngiltere'de Kumar ve Harris isimli araştırmacılar 1976-1982 yılları arasında prepusyal ada flebi sonrası takip ettikleri olguların $\% 80$ 'inin penis görünümlerinden memnun olduklarını bildirmişlerdir. ${ }^{[14]}$ Jones ve arkadaşları ise cerrahi sonrası olguların $\% 81$ 'inin genital görünümlerinden memnun olduklarını bildirmişlerdir. ${ }^{[15]}$ Yakın zamanda yapılan ve kontrol grubu içeren nispeten sınırlı sayıdaki çalışmalarda da penis algısının kontrollere göre anlamlı olarak farklı olmadığı belirtilmektedir. ${ }^{[16-19]}$ Öte yandan, özellikle eski tarihli çalışmalar başta olmak üzere ağırlıklı olarak hipospadias cerrahisi geçiren adolesan ve erişkinlerin flask haldeki penis, meatusun pozisyonu, glans şekli ve genel penis görünüşü gibi parametreler söz konusu olduğunda daha az memnun oldukları anlaşılmaktadır. ${ }^{[8,20-23]}$ Buna göre, Japonya'da yapılan bir çalışmada hipospadias onarımı yapılan grupta $\% 40,9$, kontrol grubunda ise \%34,2 oranında penil görünüşten memnuniyetsizlik saptanmıştır. ${ }^{[3]}$ Erişkin Çinlilerde yapılan bir araştırmada ise hipospadias cerrahisi ve kontrol grubunda bu oranlar sırasıyla $\% 28$ ve $\% 8$ olarak bildirilmiştir. ${ }^{[7]}$ Diğer çalışmalarda farklı cerrahi teknikler sonrası penis görünümlerinden memnun olmama oranları \%31,4-84,7 arasında bildirilmiştir. ${ }^{[4,15,24]}$ Çocukluk döneminde şiddetli hipopadias nedeniyle opere edilen ve araştırmanın yapıldığı dönemde 20-35 yaşları arasında olan 27 olgunun incelendiği bir başka araştırmada olguların 15 'i proksimal ve 12 'si de skrotal hipopadias olarak bildirilmiştir. Bu olgularda cerrahi sırasında ortalama yaş 3,3 yil, ortalama cerrahi operasyon sayısı 3,7, erken komplikasyon \%40 ve geç komplikasyon ise $\% 59$ oranlarında bildirilmiştir. Olguların \%82'si düzgün penise sahip olduklarını \%37'si ise işeme zorluğu çektiğini belirtmiştir. Bu çalışmada memnuniyet derecesinin komplikasyon oranları ile bağlantılı olduğu bulunmuştur. ${ }^{[25]}$ Penil görünümden memnun olmamanın komplikasyon haricinde hipospadias şiddeti ile de ilişkili olduğu belirtilmiştir. ${ }^{[2,4,8,13]} 1995$ yılında yapılan iki ayrı çalışmada adolesan ve erişkinlerin kendi penislerinden kontrollere kıyasla daha az memnun oldukları hipospadiasın proksimalitesi ile pe- 
nisi kısa hissetmenin korele olduğu belirtilmiştir. ${ }^{[4,8]}$ Genel kural olarak hipopadias ne kadar distalde ise penis görünümünden olguların o kadar memnun olduğu anlaşılmaktadır. ${ }^{[4,13,26-28]}$ Penis büyüklüğü de hipospadias cerrahisi geçiren olguların memnun olmama oranlarını arttıran önemli bir parametre olarak karşımıza çıkmaktadır. Çalışmalarda hipospadias cerrahisi geçiren olguların \%7-12'si penislerinin normalden küçük olduğunu belirtirken ${ }^{[29,30]} \% 30$ 'u penis boyutlarından memnun olmadığını bildirmişlerdir. ${ }^{[31]}$ Bununla ilişkili olarak çalışmaların bir kısmında olguların \%45-60'ı daha büyük penis istediklerini belirtmektedirler. [29,31,32-34] Bracka ve arkadaşlarının çalışmalarında olguların üçte biri penis boyutlarının normale göre kü̧̈ük olduğunu belirtmişlerdir. ${ }^{[6]}$ Yine bir başka araştırmada olguların \%61'i penislerinin kendileri için sorun ve endişe teşkil edecek küçüklükte olduğunu belirtmişlerdir. ${ }^{[33]}$ İsveç'te ortalama yaşları 34 yıl olan toplam 167 hastanın ortalama yaşları 33 yıl olan 169 kontrol grubu ile karşılaştırıldığı bir çalışmada demografik ve klinik veriler ışı̆̆ında hasta grubunda $\% 63$ distal, $\% 24$ orta ve $\% 13$ proksimal hipopadias olduğu anlaşılmaktadır. ${ }^{[13]}$ Hastaların penil algılama skorlarının kontrollere göre daha kötü olduğu tespit edilmiştir. Penis boyutları da hastalarda ve kontrollerde anlamlı olacak şekilde sırasıyla ortalama $9,7 \mathrm{~cm}$ ve $11,6 \mathrm{~cm}$ olarak saptanmıştır. ${ }^{[13]}$ Bundan başka, toplam 66 hipospadiaslı olgu (47 distal, 8 mid ve 11 proksimal) ile 151 kontrol olgusunun karşılaştırılmasıyla proksimal hipopadiaslarda penis uzunluğundan memnun olma daha düşük oranlarda saptanmıştır. Hipopadiaslılarda ortalama penis uzunluğu $10,8 \mathrm{~cm}$ kontrollerde ise $12,1 \mathrm{~cm}$ olarak saptanmıştır. ${ }^{[26]}$ Diğer çalışmalarda da penis büyüklüklerinin hipospadias cerrahisi geçiren heteroseksüel erkeklerde endişe kaynadığ olduğu belirtilmiştir. ${ }^{[35]}$ Hipospadias cerrahisi geçiren olgularda penis görünümleri ile ilgili bir başka durum genital yapılarından utanma ve endişe duymalarıdır. Herbenick ve arkadaşlarının çalışmalarında genital yapılarından utanma oranı \%17 olarak belirtilmiştir. ${ }^{[34]}$ Hipospadias cerrahisi geçiren olguların mevcut patoloji ve genital görünüm ya da genital algılama gibi parametreler yan yana getirildiğinde kıyafetsiz kalmalarından utanç duydukları bildirilmiştir. Örneğin bir çalışmada, penislerini küçük olarak düşünen olguların \%15'i eşlerinin yanında soyunmaktan daha az hoşlanırken bu grup penisi saklamaya çalıştığını ifade etmiştir. ${ }^{[29]}$ Benzer durum pek çok çalışmada ortaya konulmuştur. ${ }^{[4,6,8]}$ Bracka'nın çalışmasında olguların \%50'sinin toplu yerlerde duş alma ya da karşı cinsin yanında kıyafet çıkarmaktan kaçındıkları bu durumları ile alay edileceğini düşündükleri bildirilmiştir. Yine toplu tuvaletlerin olduğu alanlardan çekinildiği anlaşılmaktadır. Bu utanma duygusu pek çok çalışmada belirtilmesine rağmen tüm çalışmalarda ortaya konulamamıştır. ${ }^{[36-38]}$ Cerrahi sonrası penis ve genital görünümden memnun olmamanın nedeni bu çocuklarda sirkumsizyonun negatif etki yaratması olarak bildirilmiştir. Hipospadias cerrahisi geçiren olgularda prepusyal dokunun olmamasının kendi anomalilerini açığa çıkarmada bir endişe kaynağı olabileceği öne sürülmektedir. [8,39-41] Şiddetli hipospadiası olanların \%74’ünün genital görünümlerinden memnun olmadıkları \%30'unun ise prepusyal dokunun olmamasını anormal olarak kabul ettikleri bildirilmiştir. ${ }^{[25]}$ Sirkumsizyon kültürünün rutin olduğu ve olmadığı yerlere göre de penis algısının değişebileceği belirtilmiştir. ${ }^{[42]}$ Ruppen-Greeff ve arkadaşları sirkumsizyon sabit faktör haline getirildiğinde bile hastaların penis algısının düşük olduğunu bildirmiştir. ${ }^{[43]}$ Genital görünümden memnun olmama ve utanma duygusunda sadece penis küçüklüğü değil rezidüel penil eğrilik varlı̆̆g da etken olmuştur. Jiao ve arkadaşlarının 174 hipopadias cerrahisi geçiren olguyu değerlendirdikleri çalışmalarında penisin kozmetik yapısından memnun olmama oranları genel olarak $\% 53,5$ olarak belirtilirken penis küçüklüğü ve penil eğriliğin iki önemli faktör olduğu bildirilmiştir. ${ }^{[44]}$

Yaşın hipospadias cerrahisinde psikoseksüel gelişim ile negatif korelasyon gösterdiği bildirilmektedir. Örneğin Jones ve arkadaşlarının çalışmalarında 5 yaş öncesi opere olanlarda 5 yaş sonrası opere olanlara göre genital görünmlerinden memnun olma oranlarının daha iyi olduğu bildirilmiştir. Bunun 5 yaş öncesi hatırlamanın daha az olması ile ilişkili olduğu ileri sürülmüştür. Bu çalışmada yaşları 13-15 arasında değişen çocuklar değerlendirilmiş ve genel genital görünüm memnuniyeti $\% 81$ olarak belirtilmiştir. ${ }^{[15]}$ Çalışmalarda 18 yaş altında olanlarda ve özellikle prepubertallerde penil görünümlerinden memnun olma oranlarının daha iyi olduğu anlaşılmaktadır. ${ }^{[8,17,20]} \mathrm{Bu}$ arada hipospadias cerrahisi geçiren olguların benzer yaş grubundaki inguinal herni operasyonu geçiren olgularla karşılaştırılmaları sonrası genital görünüm algılarının kontrollere göre benzer olduğu saptanmıştır. ${ }^{[4]}$ Weber ve arkadaşlarının yaşları 6-17 yıl arasında değişen olguları inceledikleri bir araştırmada kontrol grubuna göre penis algısının farklı olmadığı belirtilmektedir. ${ }^{[17]}$ Öte yandan, yukarıdaki çalışmada olguların tersine operasyonu yapan cerrahlar ve ebeveynlerin genital algılama skorlarının daha düşük olduğu anlaşılmaktadır. Farklı çalışmalarda $13-15$ yaş arası olguların \%81'i, $18-30$ yaş arası olguların ise $\% 85$ 'i \%38 penil eğrilik saptanmasına rağmen penis görünümlerinden memnun olduklarını bildirmişlerdir. ${ }^{[19,46]}$ Bunun nedeninin daha erken yaşlarda penisin daha çok miksiyon görevine sahip olduğunun düşünülmesi, bu yaş grubundakilerin cinsel deneyim ya da karşılaştırma yapabilen yaş grubunda olmaması ile ilişkili olabileceği bildirilmektedir. İlginç bir şekilde bir araştırmada 13-21 yaş arasında şiddetli hipos- 
padias nedeniyle opere olanların \%92'si penil görünümlerinden memnun olduklarını bildirmişlerdir. ${ }^{[46]}$ Ancak, bu çalışmalarda yer yer şiddetli hipospadias tanımları arasında fark olabilmektedir. Buna göre, perineal hipopadiası şiddetli kabul eden bir gruba karşılık bazıları mid-penil ve proksimal arasındaki hipospadiasları da şiddetli olarak kabul edebilmektedir. ${ }^{[19,46]}$ Yine hastaların ve cerrahların skorlama sistemlerine göre farkll1ıklar olabilmektedir. ${ }^{[8,17]}$ Schönbucher ve arkadaşlarının hipospadias ve cinsel işlevler ilişkisini inceledikleri çalışmalarının birinde kontrol grubuna kıyasla hipospadias cerrahisi geçirenlerde genital görünüm memnuniyeti ve ilk cinsel ilişki deneyimi açısından anlamlı farklılık olmadığı bunda da en önemli iki prediktif faktörün genç yaş ve hasta bilgilendirmesi olduğu belirtilmektedir. ${ }^{[45]}$

Vajinal penetrasyonu sağlamaya ya da sürdürmeye yetecek kadar penil ereksiyonun olmaması olarak kabul edilen erektil disfonksiyonun (ED) oldukça kompleks bir yapıya sahip olduğu çok iyi bilinmektedir. Cinsel gelişim, sadece hormonlar, lokal nörotransmiterler, vasküler yapıların normal işleyişi ve gelişimi değil aynı zamanda psikolojik yanı olan bir durumdur. Vücuttaki konjenital ya da akkiz bir deformitenin kişilerin ruhsal yapılarını etkileyerek cinsel işlev bozukluğuna yol açabildiği oldukça iyi bilinmektedir. Penisteki anatomik bir bozukluğun fonksiyonel olarak cinsel birleşmeyi engelleyerek ya da kişilerin ruhsal yapısını etkileyerek cinsel işlev bozukluğuna yol açması olası nedenlerdir. Bazı çalışmalarda, her ne kadar hipospadias cerrahisi geçiren çocukların genital görünümlerinden memnun olmasalar da cinsel aktivite, koitus sayıları ve cinsel arzu açısından normal olgulara göre farklı olmadığı bildirilmektedir. ${ }^{[2,4]}$ Stephanie Vandendriessche ve arkadaşlarının yaptığı bir çalışmada hipospadias cerrahisi geçiren 10 erkek olgu yaş eşleştirilmiş kontrol grubu ile karşılaştırılmış ve sonuçta mastürbasyon, penil duyarlılık ve cinsel ilişki açısından anlamlı fark saptanmamıştır. ${ }^{[16]} 1987-1992$ yılları arasında ortalama yaşları 2,5 yıl olan olgular distal koronal ve subkoronal hipospadias nedeniyle opere edilmişlerdir. Bunlar içerisinde uzun dönem takipleri yapılan 118 olgu incelenmiş ve $\% 95$ 'inde iyi olarak kabul edilebilecek fonksiyonel ve kozmetik sonuçlar elde edilmiştir. Bu çalışmada yeniden operasyon $\% 5$, meatal stenoz $\% 2,5$, fistül $\% 1,7$ ve yara yerinin tam açılması ise bir olguda gözlenmiştir. Bunlar içerisinde yaşları 15-20 yıl arasında değişen 19 postpubertal olgunun incelenmesi sonrası seksüel problemler saptanmamıştır. ${ }^{[47]}$ 1963-1975 yılları arasında hipospadias nedeniyle opere edilen toplam 43 olgunun incelendiği bir başka çalışmada cinsel memnuniyet oranı $\% 62,8$ olarak bildirilmiştir. Memnun olanların \%22,22'sinde cer- rahi komplikasyon gözlenirken memnun olmayanların \%57,1'inde cerrahi komplikasyon gözlenmiştir. ${ }^{[4]}$ Yakın zamanda daha önceden hipospadias cerrahisi geçiren 18 yaş ve üzeri ortalaması olan 29 olgunun incelendiği bir çalışmada olguların \%82'sinin genital görünümlerinden, \%87'sinin ise idrar akımları ve cinsel fonksiyonlarından memnun oldukları anlaşılmaktadır. ${ }^{[49]} 1990$ ve 2000 yıllarında 12 yaş üstü olup hipospadias için Onlay, Mathieu, Duplay ya da Duckett teknikleri ile opere edilen olguların \%82,2'si penil görünümlerinden memnun ya da çok memnun olduklarını bildirmişlerdir. Sadece 16 yaş üstü olgular cinsel işlevler açısından incelendiği zaman ise $\% 81$ 'i normal ereksiyona sahip olduklarını bildirmişlerdir. ${ }^{[50]}$ Bazı çalışmalarda, hipospadias cerrahisinin daha düşük seksüel memnuniyet ve ejakülasyon sıklığı ile orgazmik fonksiyonların azlığına yol açtığı belirtilmektedir. [26,51,52] Bubanj ve arkadaşlarının yaptığı ve opere olan 37 hipospadias olgusunun 39 kontrol grubu ile karşılaştırdığ 1 bir çalışmada libidonun iki grup arasında benzer olduğu saptanmıştır. Yine hipospadiaslı olguların ereksiyona ulaşmaları ile ereksiyon kalitelerinin diğer gruptan anlamlı olarak farklı olmadığı ortaya konulmuştur. Hipospadiaslı olguların 13'ünün ejakülasyon zorluğu olduğu saptanmıştır. Bundan başka bu olguların daha az mastürbasyon yaptıkları, daha az cinsel ilişkiye girdikleri ve cinsel partner sayılarının daha az olduğu tespit edilmiştir. [26] Aynı çalışmada, kontrol grubunda cinsel ilişkilerden tatmin olma oranı \%76,92 olarak belirtilirken bu oran hipospadias grubunda \%51,35 olarak belirtilmektedir. [28] Hipospadias nedeniyle oral mukozal greft kullanılarak basamaklı üretroplasti yapılan bir araştırmada \%52 oranında üretral darlık saptanmıştır. Çalışma sonunda hipospadias cerrahisi geçiren olguların \%32'si seksüel ilişkilerinde iyileşme, \%52'si ise değişiklik olmadığını bildirmiştir. Bundan başka \%40'ı ejakülasyonlarının azaldığını $\% 45$ 'i değişmediğini bildirmiştir. Penil eğrilik \%23, penis uzunluğunda kayıp \%55 ve penil sensitivitede değişiklik ise $\% 45$ olarak bildirilmiştir. ${ }^{[53]}$ Çocukluk döneminde hipopadias cerrahisi geçiren 119 olgu incelenmiştir. Olgular glanüler hipospadias, distal hipospadias ve proksimal hipospadias olmak üzere üç gruba ayrılmışlardır. Grup 1 ve 2'deki tüm hastalar ile grup 3'teki olguların \%11'i penil görünümlerinden memnun olduklarını açıklamışlardir. Grup 1'de $\% 8,9$, grup 2 ve grup 3'te ise sirasiyla $\% 50$ ve $\% 72,2$ oranlarında orta düzeyde ED olduğu bildirilmiştir. Olguların \%83,2'si erken ejakülasyon olduğunu bildirmişlerdir. Grup 1 ve grup 2'deki olguların üçte ikisi seksüel yaşamlarını mükemmel olarak tariflemektedirler. Grup 3'te seksüel kalitenin bir parçada olsa azalması yakınması tüm hastalarda bulunmuştur. Bunlardan \%5,6's1 çok kötü olduğunu ifade etmektedir. ${ }^{[28]} 2002-2007$ yıl- 
ları arasında daha önce başarısız üretroplasti öyküsü olup üretroplasti için başvuran 163 olgunun incelendiği bir araştırmada ortalama yaş 39,7 yıl olarak belirtilmektedir. Olguların IIEF-6 ile yapılan değerlendirmelerinde şiddetli, orta ve hafif ED oranları sırasıyla \%22,1, \%3,7 ve \%28,2 olarak saptanmıştır. Cerrahi sonrası \%85 oranında artmış ya da aynı kalan cinsel işlevler belirtilmiştir. ${ }^{[54]}$ Bazı araştırmalarda orta ve proksimal hipospadiası olanlarda seksüel doyum kontrollere göre daha olarak kötü saptanırken distal olanlarda anlamlı fark saptanmamıştır. ${ }^{[55]} \mathrm{Bu}$ memnuniyet özellikle 3 yaş altı opere edilenlerle tek aşamalı tedavi olanlarda daha yüksek saptanmıştır. ${ }^{[55]}$ Oral mukozal greft üretroplasti ile hipospadias cerrahisi yapılan ve inceleme sırasında 18 yaş ve üzerinde olan 16 olgunun incelenmesiyle ortalam 4,7 yıllık takiplerde maksimum

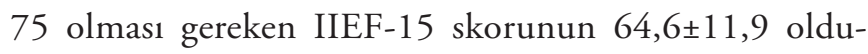
ğu bildirilmiştir. Erektil fonksiyon mükemmel olarak belirtilmiştir. Toplam üç olguda ejakülasyon zorluğu saptanmıştır. Seksüel aktif 10 olgunun orta derecede ve $(n=6)$ ve oldukça memnun oldukları $(n=4)$ bildirilmiştir. $\mathrm{Bu}$ çalışmada komplikasyonlar, penil görünüm memnuniyeti IIEF-15 ve seksüel memnuniyetle ilişkisiz saptanmıştır. ${ }^{[22]}$ Kiss ve arkadaşlarının hipospadias cerrahisini 3-7 yaşları arasında yaptıkları bir çalışmada ortalama operasyon zamanındaki yaş 4,5 yıl olarak belirtilmiştir. Buna göre yaşları 24-42 yıl arasında değişen olgular kontrol grubu ile karşılaştırılmıştır. Bu olguların cinsel yaşamlarından memnun olma oranları 1 ile 10 arasındaki skalaya göre kontrol grubundan anlamlı olmasa da daha yüksek olarak saptanmıştır. Bu çalışmada olguların \%79'u bir parçada olsa idrar akım hızında deviasyon olduğunu belirtmektedirler. ${ }^{[56]}$ Hipospadias cerrahisi geçiren olgularda cinsel ilişki sırasında penil görünümden kaynaklanan utanma nedeniyle cinsel inhibisyon söz konusu olabilmektedir. ${ }^{[57]}$ Buna göre, Schönbucher ve arkadaşlarının 13 çalışmayı incelediği derlemesinde de genel olarak hipospadiaslı olgularda genital görünümden memnun olmama ve cinsel inhibisyonun daha fazla olduğu bildirilmektedir. ${ }^{[58]}$

Bazı çalışmalarda bu olguların benzer özelliklere sahip ancak hipospadiası olmayanlara göre daha az ve daha geç dönemlerde cinsel ilişkiye girdikleri belirtilmektedir. Bir çalışmada, proksimal hipospadias nedeniyle iki aşamalı cerrahi girişim geçiren toplam 92 olgu incelenmiştir. Bu olguların 42'si uzun dönem takip edilmişlerdir. Bu olgularında kontrol grubuna göre cinsel deneyimlerini daha geç yaşlarda yaşadıkları bildirilmiştir. Diğer bir araştırmada, cerrahi girişim geçiren olgularda ortalama cinsel ilişki yaşı 16,9 yıl olarak bildirilirken normal erişkin kontrol grubunda bu ortalama 16,6 yıl olarak saptanmıştır. ${ }^{[59]}$ Aynı çalışmada, olgular bir başka bakış açısına göre 12 yaş ve öncesi ile 13 yaş ve sonrası opere olanlar olmak üzere iki gruba ayrılarak incelenmişlerdir. Eski ve yeni grupta ilk cinsel ilişki başlangıcı 15,5 yıl ve 17,6 yıl olarak saptanmıştır. ${ }^{[59]}$ Berg ve arkadaşlarının 1981 yılında yaptıkları ve hipospadias nedeniyle opere olan 34 olguyu 36 kontrol olgusuyla karşılaştırdıkları çalışmalarında, hipospadias olgularının daha az cinsel aktiviteye sahip oldukları belirtilmiştir. Buna karşın iki grup arasında ejakülasyonun ilk oluştuğu yaş ile fertilite arasında anlamlı fark saptanmamışır. ${ }^{[60]} 1973-1998$ yılları arasında hipospadias nedeniyle opere edilen ve çalışmanın yapıldığı sırada 18 yaş ve üzerinde olan olgular Uluslararası Prostat Semptom Skoru (IPSS), Uluslar arası Cinsel İşlev Değerlendirme İndeksi (IIEF-5), evlilik ve babalık deneyimi gibi valide ve valide olmayan formlarla değerlendirilmişlerdir. Bu çalışmada değerlendirilen olgulardan iki aşamalı ve tek aşamalı operasyon geçirenlerin sayısı sırasıyla 79 ve 12 olarak belirtilirken 17 olguya yeniden operasyon yapma ihtiyacı olmuştur. Toplam 57 olguda orta denilen (31 glandüler, 26 penil), 36 olguda ise proksimal denilen (13 penoskrotal, 23 skrotal-perineal) ve 15 'ine ise tam olarak ortaya konulamayan tipte operasyon yapılmıştır. Çoklu değişkenli analizlerde cinsel ilişki deneyimi orta decedeki tip operasyonla ilişkili bulunmuştur. ${ }^{[61]}$ Sosyal medyanın günümüzde oldukça yaygın olarak kullanıldığı bilinen bir gerçektir. Sosyal medya üzerinden yapılan bir araştırmada 736 olgunun incelenmesi sonrası \%7,1 ( $\mathrm{n}=52)$ oranında tedavi edilmemiş hipospadias olgusu ortaya çıkmıştır. Bu olguların Ekeklerde Cinsel Sağlık Değerlendirme Formu (SHIM), IPSS skorları ve cinsel ilişkiyi zora sokacak penil eğrilikleri ve idrar yapma zorlukları kötü olarak saptanmıştır. Orta ve şiddetli hipospadias olarak ayrıldıklarında ise şiddetli olanlarda negatif etkilerin daha kötü olduğu görülmüştür. ${ }^{[62]}$ Hipospadias cerrahisi geçiren 33 olgunun incelendiği bir araştırmada bir olgunun penis eğriliği nedeniyle ilişki zorluğu yaşadığı bildirilmiştir. ${ }^{[63]}$

Sonuç olarak erkeklerde nispeten sık görülen bir penil anomali olan hipospadias cerrahisinde anatomik bozukluğun düzeltilmesi sonrası meatusun uygun lokalizasyona getirilmesi ve bununla bağlantılı olarak normal miksiyonun sağlanmasının ön planda düşünüldüğü görülmektedir. Hipospadias cerrahisi sonrası takiplerde erkek cinsel işlev bozukluğu ile ilgili olarak son derece sınırlı sayıda çalışmanın olduğu anlaşılmaktadır. Hipospadias cerrahisi geçirenlerde uzun dönemde cinsel işlevler ve cinsel tatmin skorlarının giderek arttığı görülse de uzun dönemli farklı yaş grupları$\mathrm{n} ı$ içeren geniş olgu sayısına ulaşan çalışmaların bu konuda daha aydınlatıcı bilgiler verebileceği söylenebilir. 


\section{Kaynaklar}

1. Dolk H, Loane M, Garne E. The prevalence of congenital anomalies in Europe. Adv Exp Med Biol 2010;686:349-64. doi: 10.1007/978-90-481-9485-8_20

2. Mondaini N, Ponchietti R, Bonafe M, Biscioni S, Di Loro F, Agostini P, et al. Hypospadias: incidence and effects onpsychosexual development as evaluated with the Minnesota Multiphasic Personality Inventory Test in a sample of 11649 Italian men. Urol Int 2002;68:81-5.

3. Moriya K, Kakizaki H, Tanaka H, et al. Long-term cosmetic and sexual outcome of hypospadias surgery: norm related study in adolescence. J Urol 2006;176:1889-93. doi: 10.1016/S00225347(06)00600-8

4. Mureau MA, Slijper FM, Nijman RJ, van der Meulen JC, Verhulst FC, Slob AK. Psychosexual adjustment of children and adolescents after different types ofhypospadias surgery: a norm-related study. J Urol 1995;154:1902-7.

5. Baskin L. Hypospadias and urethral development. J Urol 2000;163:951-6.

6. Bracka A. A long-term view of hypospadias. Br J Plast Surg 1989;42:251-5.

7. Wang WW, Deng CH, Chen LW, Zhao LY, Mo JC, Tu XA. Psychosexual adjustment and age factors in 130 men undergonehypospadias surgery in a Chinese hospital. Andrologia 2010;42:384-8. doi: 10.1111/j.1439-0272.2010.01061.x

8. Mureau MAM, Slijper FME, Slob AK, Verhulst FC. Genital perception of children, adolescents, and adults operated onfor hypospadias: a comparative study. J Sex Res 1995;32:289-98.

9. Aho MO, Tammela OK, Somppi EM, Tammela TL. Sexual and social life of men operated in childhood for hypospadias and phimosis. A comparative study. Eur Urol 2000;37:95-100.

10. Kiss A, Sulya B, Szász AM, Romics I, Kelemen Z, Tóth J, et al. Long-term psychological and sexual outcomes of severe penile hypospadias repair. J Sex Med 2011;8:1529-39. doi: 10.1111/j.1743-6109.2010.02120.x

11. Merksz M, Sulya B, Szasz M, Romics I, Kelemen Z, Nyirady P, et al. Long-term psychosexual consequences of hypospadias repair. J Pediatr Urol 2010;6:S81. doi: 10.1016/j.jpurol.2010.02.153

12. Eray N, Dogangun B, Kayaalp L, Emir H, Soylet Y, Danismend N, et al. Emotional effects of hypospadias surgery on Turkish boys. J Pediatr Urol 2005;1:75-80. doi: 10.1016/j.jpurol.2004.12.003

13. Örtqvist L, Fossum M, Andersson M, Nordenstrom A, Frisen L, Holmdahl G, et al. Long-term follow-up of adult men born with hypospadias: urological and cosmetic results. J Urol 2015; 193:97581. doi: 10.1016/j.juro.2014.09.103

14. Kumar MV, Harris DL. A long term review of hypospadias repaired by split preputial flap technique (Harris). Br J Plast Surg 1994; $47: 236-40$.

15. Jones BC, O'Brien M, Chase J, Southwell BR, Hutson JM. Early hypospadias surgery may lead to a better long-term psychosexual outcome. J Urol 2009;182(4 Suppl):1744-9. doi: 10.1016/j. juro.2009.02.089

16. Vandendriessche S, Baeyens D, Van Hoecke E, et al. Body image and sexuality in adolescents after hypospadias surgery. J Pediatr Urol 2010;6:54-9. doi: 10.1016/j.jpurol.2009.04.009

17. Weber DM, Landolt MA, Gobet R, Kalisch M, Greeff NK. The Penile Perception Score: an instrument enabling evaluation by surgeons and patient self-assessment after hypospadias repair. J Urol 2013;189:189-93. doi: 10.1016/j.juro.2012.08.178

18. Wouters G, Rynja S, van Schaijk M, Kok ET, de Jong TP, de Kort LM. Long term follow up into adulthood of boys operated on for hypospadias: A study into functional and cosmetic results. J Pediatr Urol 2009;5:S56.

19. Fraumann SA, Stephany HA, Clayton DB, Thomas JC, Pope JC, 4th, Adams MC, et al. Long-term follow-up of children who underwent severe hypospadias repair using an online survey with validated questionnaires. J Pediatr Urol 2014;10:446-50. doi: 10.1016/j.jpurol.2014.01.015

20. Glassman CN, Machlus BJ, Kelalis PP. Urethroplasty for hypospadias: long-term results. Urol Clin North Am 1980;7:43741.

21. Rynja SP, de Jong TP, Bosch JL, de Kort LM. Functional, cosmetic and psychosexual results in adult men who underwent hypospadias correction in childhood. J Pediatr Urol 2011;7:504-15. doi: 10.1016/j.jpurol.2011.02.008

22. Nelson CP, Bloom DA, Kinast R, Wei JT, Park JM. Patientreported sexual function after oral mucosa graft urethroplasty for hypospadias. Urology 2005;66:1086-9. doi: 10.1016/j. urology.2005.05.057

23. Hoag CC, Gotto GT, Morrison KB, et al. Long-term functional outcome and satisfaction of patients with hypospadias repaired inchildhood. Can Urol Assoc J 2008;2:23-31.

24. Mor Y, Ramon J, Jonas P. Is only meatoplasty a legitimate surgical solution for extreme distal hypospadias. A long-term follow-up after adolescence? BJU Int 2000;85:501-3.

25. Aulagne MB, Harper L, de Napoli-Cocci S, Bondonny JM, Dobremez E. Long-term outcome of severe hypospadias. J Pediatr Urol 2010;6:469-72. doi: 10.1016/j.jpurol.2009.12.005

26. Rynja SP, Wouters GA, Van Schaijk M, et al. Long-term followup of hypospadias: Functional and cosmetic results. J Urol 2009;182(4 Suppl):1736-43. doi: 10.1016/j.juro.2009.03.073

27. Liu G, Yuan J, Feng J, Geng J, Zhang W, Zhou X, et al. Factors affecting the long-term results of hypospadias repairs. J Pediatr Surg 2006;41:554-9. doi: 10.1016/j.jpedsurg.2005.11.051

28. Chertin B, Natsheh A, Ben-Zion I, et al. Objective and subjective sexual outcomes in adult patients after hypospadias repair performed in childhood. J Urol 2013;190(4 Suppl):1556-60. doi: 10.1016/j.juro.2012.12.104

29. Lever J, Frederick DA, Peplau LA. Does size matter? Men's and women's views on penis size across the lifespan. Psychol Men Masc 2006;7:129-43. doi: 10.1037/1524-9220.7.3.129

30. Grov C, Parsons JT, Bimbi DS. The association between penis size and sexual health among men who have sex with men. Arch Sex Behav 2010;39:788-97. doi: 10.1007/s10508-008-9439-5

31. Veale D, Eshkevari E, Read J, Miles S, Troglia A, Phillips R, et al. Beliefs about penis size: Validation of a scale for men ashamed about their penis size. J Sex Med 2014;11:84-92. doi: 10.1111/ jsm. 12294

32. Martins Y, Tiggemann M, Churchett L. The shape of things to come: Gay men's satisfaction with specific body parts. Psychol Men Masc 2008;9:248-56.

33. Tiggemann M, Martins Y, Churchett L. Beyond muscles: Unexplored parts of men's body image. J Health Psychol 2008;13:1163-72. doi: 10.1177/1359105308095971

34. Herbenick D, Schick V, Reece M, Sanders SA, Fortenberry JD. The development and validation of the Male Genital Self-Image Scale: Results from a nationally representative probability sample of men in the United States. J Sex Med 2013;10:1516-25. doi: $10.1111 /$ jsm. 12124

35. Johnston L, McLellan T, McKinlay A. (Perceived) size really does matter: Male dissatisfaction with penis size. Psychol Men Masc 2014;15:225-8. doi: 10.1037/a0033264 
36. Ruppen-Greeff NK, Landolt MA, Gobet R, Weber DM. Appraisal of adult genitalia after hypospadias repair: Do laypersons mind the difference? J Pediatr Urol 2016;12:32.e1-8. doi: 10.1016/j. jpurol.2015.09.012

37. Hatipoglu NK, Bodakci MN, Soylemez H, Sancaktutar AA, Atar M, Penbegul N, Cakmakci S. Tubularized incised plate repair in circumcised adults. Med Glas (Zenica) 2013;10:316-20.

38. Cakan M, Yalçinkaya F, Demirel F, Aldemir M, Altuğ U. The midterm success rates of tubularized incised plate urethroplasty in reoperative patients with distal or midpenile hypospadias. Pediatr Surg Int 2005;21:973-6. doi: 10.1007/s00383-005-1555-x

39. Mureau MA, Slijper FM, Slob AK, Verhulst FC, Nijman RJ. Satisfaction with penile appearance after hypospadias surgery: the patient and surgeon view. J Urol 1996;155:703-6.

40. Adams J, Bracka A. Reconstructive surgery for hypospadias: A systematic review of long-term patient satisfaction with cosmetic outcomes. Indian J Urol 2016;32:93-102. doi: 10.4103/09701591.179178

41. Mureau MA. Psychosexual and psychosocial development of patients with hypospadias. Ned Tijdschr Geneeskd 1997;141:18891.

42. Bracka A. Sexuality after hypospadias repair. BJU Int 1999;83:2933.

43. Ruppen-Greeff NK, Weber DM, Gobet R, Landolt MA. Healthrelated quality of life in men with corrected hypospadias: An explorative study. J Pediatr Urol 2013;9:551-8. doi: 10.1016/j. jpurol.2013.04.016

44. Jiao $\mathrm{C}, \mathrm{Wu} \mathrm{R}, \mathrm{Xu} \mathrm{X}, \mathrm{Yu} \mathrm{Q}$. Long-term outcome of penile appearance and sexual function after hypospadiasrepairs: situation and relation. Int Urol Nephrol 2011;43:47-54. doi: 10.1007/ s11255-010-9775-y

45. Schönbucher VB, Landolt MA, Gobet R, Weber DM. Psychosexual development of children and adolescents with hypospadias. J Sex Med 2008;5:1365-73. doi: 10.1111/j.1743-6109.2007.00742.x

46. Lam PN, Greenfield SP, Williot P. 2-stage repair in infancy for severe hypospadias with chordee: Long-term results after puberty. J Urol 2005;174(4 Pt 2):1567-72.

47. Caione P, Capozza N, Lais A, Ferro F, Matarazzo E, Nappo S. Long-term results of distal urethral advancement glanuloplasty for distal hypospadias. J Urol 1997;158(3 Pt 2):1168-70.

48. Aho MO, Tammela OK, Tammela TL. Aspects of adult satisfaction with the result of surgery for hypospadias performed in childhood. Eur Urol 1997;32:218-22.

49. Nozohoor Ekmark A, Arnbjörnsson E, Svensson H, Hansson E. Patient-reported long-term outcome after primary hypospadias repair. J Plast Surg Hand Surg 2017;51:172-7. doi: 10.1080/2000656X.2016.1212713

50. Thiry S, Saussez T, Dormeus S, Tombal B, Wese FX, Feyaerts A. Long-Term Functional, Cosmetic and Sexual Outcomes of
Hypospadias Correction Performed in Childhood. Urol Int 2015;95:137-41. doi: 10.1159/000430500

51. Bubanj TB, Perovic SV, Milicevic RM, et al. Sexual behavior and sexualfunction of adults after hypospadias surgery: a comparativestudy. J Urol 2004;171:1876-9. doi: 10.1097/01. ju.0000119337.19471.51

52. Wilcox D, Snodgrass W. Long-term outcome following hypospadias repair. World J Urol 2006;24:240-3. doi: 10.1007/ s00345-006-0059-1

53. Patel DP, Elliott SP, Voelzke BB, Erickson BA, McClung CD, Presson AP, Zhang C, Myers JB. Trauma and Urologic Reconstruction Network of Surgeons (TURNS). Patient-Reported Sexual Function After Staged Penile Urethroplasty. Urology 2015;86:395-400.

54. Stein DM, Gonzalez CM, Barbagli G, Cimino S, Madonia M, Sansalone S. Erectile function in men with failed hypospadias repair. Arch Esp Urol 2014;67:152-6.

55. Wei Y, Li XD, Xu N, Xue XY, Zheng QS, Jiang T, Huang JB, Sun $\mathrm{XL}$. Penile appearance, sexual function and sexual satisfaction of hypospadias patients after surgery: a long-term follow-up study. Zhonghua Nan Ke Xue 2014;20:48-53.

56. Kiss A, Sulya B, Szász AM, et al. Long-term psychological and sexual outcomes of severe penile hypospadias repair. J Sex Med 2011;8:1529-39. doi: 10.1111/j.1743-6109.2010.02120.x

57. Mureau MA, Slijper FM, Slob AK, Verhulst FC. Psychosocial functioning of children, adolescents, and adults following hypospadiassurgery: a comparative study. J Pediatr Psychol 1997;22:371-87.

58. Schönbucher VB, Weber DM, Landolt MA. Psychosocial adjustment, health-related quality of life, and psychosexual development of boys with hypospadias: a systematic review. J Pediatr Psychol 2008;33:520-35. doi: 10.1093/jpepsy/jsm098

59. Avellán L. The development of puberty, the sexual début and sexual function in hypospadiacs. Scand J Plast Reconstr Surg 1976;10:29-44.

60. Berg R, Svensson J, Aström G. Social and sexual adjustment of men operated for hypospadias during childhood: a controlled study. J Urol 1981;125:313-7.

61. Kanematsu A, Higuchi Y, Tanaka S, Hashimoto T, Nojima M, Yamamoto S. Multivariate Analysis of the Factors Associated With Sexual Intercourse, Marriage, and Paternity of Hypospadias Patients. J Sex Med 2016;13:1488-95. doi: 10.1016/j. jsxm.2016.07.014

62. Schlomer B, Breyer B, Copp H, Baskin L, DiSandro M. Do adult men with untreated hypospadias have adverse outcomes? A pilot study using a social media advertised survey. J Pediatr Urol 2014;10:672-9. doi: 10.1016/j.jpurol.2014.01.024

63. Svensson J, Berg R. Micturition studies and sexual function in operated hypospadiacs. Br J Urol 1983;55:422-6. 